\title{
Second closed mitral valvotomy for recurrent mitral stenosis
}

\author{
KENNETH FRASER AND BRIAN A. SUGDEN \\ From the Department of Surgery, Western Infirmary, Glasgow, UK
}

Fraser, K., and Sugden, B. A. (1977). Thorax, 32, 759-762. Second closed mitral valvotomy for recurrent mitral stenosis. Sixty-seven patients undergoing a second closed mitral valvotomy between 1957 and 1974 have been reviewed. Since 1951, 510 patients have had a primary closed valvotomy in the same unit. The incidence of restenosis severe enough to warrant further surgery is higher after a finger fracture procedure (40\%) than after a Tubbs dilator valvotomy $(9 \cdot 2 \%)$. There is an operative mortality of $10.4 \%$, and a further late mortality of $23.8 \%$ after a second closed valvotomy. Of the surviving patients, $70.5 \%$ have had a good or excellent result. The group with poor results is characterised by the presence of a calcified fixed valve, making valvotomy difficult and incomplete. In the presence of a non-calcified valve, a second valvotomy still has a place when surgery for restenosis is required.

The number of patients being submitted to a second closed valvotomy has diminished because of the current widespread use of open-heart procedures and valve replacement. There is little published work on the results of second valvotomies, and it was considered that some useful information might be obtained by reviewing our experience.

\section{Patients and methods}

All patients undergoing a second closed mitral valvotomy for recurrent mitral stenosis at the Western Infirmary, Glasgow are included. The operations were performed between August 1957 and July 1974, using the Tubbs transventricular mitral valve dilator (Logan and Turner, 1959).

Sixty-seven patients required a second valvotomy. During the same period a further 359 primary closed valvotomies were performed in a similar manner. From 1951 mitral valvotomy was performed using the finger fracture technique, and 151 patients had a closed primary valvotomy by this method. In total, therefore, 510 primary valvotomies have been performed in addition to the 67 patients having a second valvotomy.

Of these 67 patients, 44 survivors were available for review, which took the form of outpatient attendance for current assessment at either the cardiac or surgical clinics in 37 patients. Six patients could not attend, usually due to the travelling required, and those patients and their general practitioners completed questionnaires for the purpose of assessment. One patient could not be traced.

\section{Results}

Since the introduction of the Tubbs dilator in 1957, the incidence of mitral restenosis severe enough to necessitate a second operation has fallen. The histogram (Figure), shows the annual number of primary valvotomies performed since 1951 and the number each year requiring further surgery for restenosis later, whether closed valvotomy, open valvotomy, or mitral valve replacement. Of the 151 finger fracture primary valvotomies carried out up to $1957,61(40 \%)$ have had a second operation compared to $33(9 \cdot 2 \%)$ of the 359 dilator primary valvotomies. There has, of course, been a longer follow-up for those having a finger fracture valvotomy, but a review of the time interval between the first and second operations reveals that $74 \%$ of the finger fracture group had their second operation within 10 years of the first, indicating that time alone is not responsible for the difference in incidence of restenosis.

Some of the patients on whom we had performed the first valvotomy had their second operation elsewhere; similarly, of the 67 patients having a second closed valvotomy in this series, some had had the primary operation in a different unit. Fifty-eight of the 67 had an original finger fracture valvotomy, and 


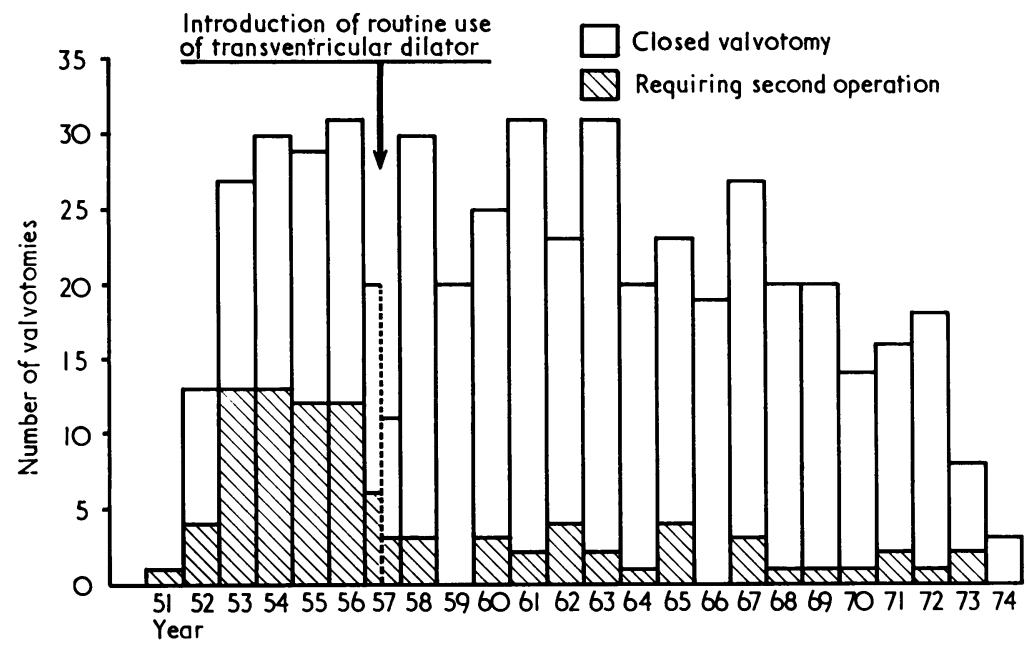

Figure Primary closed valvotomy and annual incidence of re-operation. in only nine was a dilator used. This gives some idea of the improved results obtained since the mitral valve dilator was introduced.

Seven of the 67 patients died shortly after a second closed valvotomy, an operative mortality of $10.4 \%$. The usual cause of death was early cardiac and/or respiratory failure, although two patients died as a result of haemorrhage during the operation. There have been 16 late deaths $(23.8 \%), 15$ due to continuing mitral valve disease and its associated problems. The other patient died from an unrelated condition.

The clinical state of the surviving 44 patients was graded by the method previously described (Fraser $\boldsymbol{e} t$ al., 1976), the one patient lost to follow-up being excluded. Table 1 shows the results and gives some indication of the time interval after the second closed valvotomy. Of these patients $81.8 \%$ are at present in good or excellent health, many after at least 10 years. Excluding the five patients who had a mitral valve replacement subsequent to their second valvotomy, there are still 31 patients $(70.5 \%)$ in good health after two closed valvotomies.

Of equal importance is the analysis of the 12 patients not doing well after a second valvotomy,

Table 1 Clinical assessment after second closed mitral valvotomy in 44 patients

\begin{tabular}{lllllll}
\hline Assessment & \multicolumn{2}{l}{ Length of follow-up } & & Total & $\begin{array}{l}\text { Subsequent } \\
\text { mitral valve } \\
\text { replacement }\end{array}$ \\
\cline { 2 - 3 } & $5 y r$ & $5-10 y r$ & $10 y r$ & & & \\
Very good & 7 & 6 & 10 & $23(52 \cdot 3 \%)$ & 1 \\
Good & 1 & 6 & 6 & $13(29 \cdot 5 \%)$ & 4 \\
Poor & 2 & 1 & 4 & $7(15 \cdot 9 \%)$ & - \\
Lost to & & & & $1(2 \cdot 3 \%)$ \\
review & & & & & 1 \\
\hline
\end{tabular}

including the five patients who needed valve replacements later. Several factors assessed at operation may account for the poor result.

The operator assessed the valve size digitally both before and after valvotomy, and the results are shown in Table 2. There is no difference between the degree of stenosis and the size of split achieved at either the primary or second valvotomy in patients having a very good result and those with a poor outcome. An inadequate split, therefore, cannot alone account for the poor results. More relevant is the completeness of split achieved. The full operative details are available for only 10 of the 12 patients with poor results. Seven of these had an incomplete split not reaching the atrioventricular ring. A similar incomplete operation was recorded in only four of the 31 patients doing well. When the valvotomy was incomplete the valve was found to be fixed, funnelled, and often heavily calcified. Where the valve was mobile and non-calcified, total separation of the commissures was always achieved.

Of the 12 poor results after a second closed valvotomy, five patients are doing well following mitral valve replacement. Two are awaiting valve replacement, and one has refused further surgery. One patient awaits cardiac catheterisation with a view to possible valve replacement. Two patients are disabled as a result of cerebral embolism and another has a severe anxiety neurosis which has contributed to his deterioration.

\section{Discussion}

We have previously reported results which show that a primary closed valvotomy using the mitral valve dilator is an acceptable and safe means of relieving a 
Table 2 Operative assessment of mitral valve size

\begin{tabular}{|c|c|c|c|c|c|c|c|c|c|c|}
\hline \multirow[t]{2}{*}{ Operation } & & \multicolumn{8}{|c|}{ Valve size $(\mathrm{cm})$} & \multirow{2}{*}{$\begin{array}{l}\text { Present grading after } \\
\text { second valvotomy }\end{array}$} \\
\hline & & $1 \cdot 0$ & $1 \cdot 5$ & $2 \cdot 0$ & $2 \cdot 5$ & $3 \cdot 0$ & $3 \cdot 5$ & $4 \cdot 0$ & 4.5 & \\
\hline First valvotomy & $\begin{array}{l}\text { before } \\
\text { after }\end{array}$ & 12 & 6 & 4 & 9 & 3 & 2 & & & Very good (22 patients) \\
\hline Second valvotomy & $\begin{array}{l}\text { before } \\
\text { after }\end{array}$ & 13 & 7 & 1 & & 6 & 6 & 7 & 1 & \\
\hline First valvotomy & $\begin{array}{l}\text { before } \\
\text { after }\end{array}$ & 5 & 2 & & 3 & 2 & 2 & & & Good ( 9 patients) \\
\hline Second valvotomy & $\begin{array}{l}\text { before } \\
\text { after }\end{array}$ & 4 & 4 & & & & 4 & 3 & & \\
\hline First valvotomy & $\begin{array}{l}\text { before } \\
\text { after }\end{array}$ & 3 & 4 & 3 & 2 & 2 & 4 & 1 & 1 & Poor (12 patients) \\
\hline Second valvotomy & $\begin{array}{l}\text { before } \\
\text { after }\end{array}$ & 5 & 4 & & 1 & 1 & 4 & 3 & 1 & \\
\hline
\end{tabular}

stenosed valve (Fraser et al., 1976), as others have already shown (Ellis et al., 1973). This seems a good reason for considering a second closed valvotomy in the event of the development of restenosis. There are those who argue in favour of open mitral valvotomy or valve replacement in these cases, or at least having a heart-lung machine available. We think our results show that there is a case for a second valvotomy, provided careful screening is performed to exclude valves unsuitable for this procedure. When the mortality, morbidity, cost, and often long waiting lists for open-heart surgery are considered, repeat closed valvotomy offers some advantages.

In our experience, there is a higher operative mortality of second closed valvotomy $(10.4 \%)$ compared with the primary procedure $(4 \cdot 2 \%)$. This finding is confirmed by other reports. Bryant and Trinkle (1971) report a mortality of $6.3 \%$ for the second valvotomy and $4 \%$ for the primary operation. Ellis and Harken (1964) had an operative mortality of $5.8 \%$ for second operations. Smith and Belcher (1970) confirmed that patients with calcified valves do not do well after a second closed valvotomy. The operative mortality was $28 \%$ in their 32 patients. The operative mortality in our series is higher than that reported after mitral valve replacement, but, in our opinion, the availability of a heart-lung machine may have benefited only the two patients who died as a result of haemorrhage. Technical difficulties at a second closed valvotomy have not been a major obstacle when the procedure was performed by an experienced surgeon.

The late result after a second closed valvotomy compares well with that of the primary operation. Ellis et al. (1973), reporting the results in a large series of closed valvotomies, eomment on the marked improvement that may be gained after a second and even a third closed valvotomy. The late result in 139 patients having a second valvotomy was nearly as good as after a primary valvotomy (Ellis and Harken, 1964). In our own analysis of closed primary valvotomy (Fraser et al., 1976), 79\% of survivors had a good result which was maintained $(74 \%$ after 10 years). After a second valvotomy $70 \%$ have a good result, but after 10 years only $21 \%$.

Our experience demonstrates that a second closed valvotomy should be avoided in patients with fixed calcified valves. This confirms the conclusions of Smith and Belcher (1970), who reviewed 32 patients with calcified valves. They found that the results did not justify a second operation and would not advocate a closed valvotomy in these cases.

Operative treatment for mitral stenosis is palliative, and our results suggest that a second closed valvotomy is an effective form of palliation. Ankeney (1967) made his choice of operation in order 'to have the greatest number of patients live the longest time, in the best possible condition,' and, when dealing with the problem of restenosis, a second closed valvotomy must seriously be considered to fulfil these criteria.

We acknowledge the assistance of Mr. M. Turner, who performed several of these operations, and also the secretarial help given by Mrs. Elizabeth Aitchison and Mrs. Isabel Gray.

\section{References}

Ankeney, J. L. (1967). Indications for closed- or openheart surgery for mitral stenosis. Annals of Thoracic Surgery, 3, 389-405.

Bryant, L. R., and Trinkle, J. K. (1971). Mitral valvotomy in the valve replacement era. Annals of Surgery, 173, 1024-1028.

Ellis, L. B., and Harken, D. E. (1964). Closed valvulo- 
plasty for mitral stenosis. New England Journal of Medicine, 270, 643-650.

Ellis, L. B., Singh, J. B., Morales, D. D., and Harken, D. E. (1973). Fifteen to twenty year study of one thousand patients undergoing closed mitral valvuloplasty. Circulation, 48, 357-364.

Fraser, K., Turner, M. A., and Sugden, B. A. (1976). Closed mitral valvotomy. British Medical Journal, 2, 352-353.
Logan, A., and Turner, R. W. D. (1959). Surgical treatment of mitral stenosis. Lancet, 2, 874-880.

Smith, G. H., and Belcher, J. R. (1970). Valvotomy in calcific mitral stenosis. British Heart Journal, 32, 198-202.

Requests for reprints to: K. Fraser, FRCS, Department of Surgery, Western Infirmary, Glasgow G11 6NT, UK. 